\title{
Glutamate Receptors in Schizophrenia: A Review
}

\author{
Shivani Lodha ${ }^{1, *}$, Shagun Upadhyay ${ }^{2}$, Khemraj Singh Baghel ${ }^{3}$, Yusra Ahmad ${ }^{1}$
}

\begin{abstract}
Shivani Lodha ${ }^{1, *}$, Shagun Upadhyay², Khemraj Singh Baghel $^{3}$, Yusra Ahmad ${ }^{1}$

${ }^{1}$ Faculty of Pharmacy, Uttarakhand Technical University, Dehradun, Uttarakhand, INDIA.

2 Department of Pharmacy, Kalaniketan Polytechnic College, Jabalpur, Madhya Pradesh, INDIA.

${ }^{3}$ Molecular Pathology Scientist, Biogenex Life Science Pvt. Ltd. Adibatla, Telangana, INDIA.
\end{abstract}

\section{Correspondence}

Mrs. Shivani Lodha

Faculty of Pharmacy, Uttarakhand Technical University, Dehradun-248007, Uttarakhand, INDIA.

Phone no: +91 0761-8989203524

E-mail: shivaniveersingh21@gmail.com

History

- Submission Date: 20-06-2020;

- Review completed: 18-07-2020;

- Accepted Date: 03-08-2020.

DOI : 10.5530/fra.2020.1.1

Article Available online

http://www.antiox.org

\section{Copyright}

(C) 2020 Phcog.Net. This is an openaccess article distributed under the terms of the Creative Commons Attribution 4.0 International license.

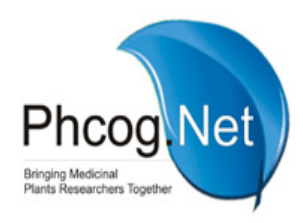

\begin{abstract}
The pathophysiology of schizophrenic shows the dysfunction of Glutamate receptors. The inotropic subtypes The NMDA, AMPA and kinate receptors out of various glutamate receptors are most commonly associated. In postmortem brain samples from schizophrenics and controls several levels of gene expression of glutamate receptors were studied. Even though there exist slight inconsistency from various studies certain points. There is an abnormal reduction in the AMPA receptor expression in the schizophrenic hippocampus, including reduced subunit transcript level, protein level and also binding sites. In hippocampus related changes are also seen in the kinate receptor expression. In some cortical regions in schizophrenia NMDAR1 shows abnormal expression. NMDDAR1 is the obligate NMDA receptor subunit. The current review ellustrates the theory of glutamate neurotransmission abnormality in schizophrenia.
\end{abstract}

Key words: Schizophrenia, Glutamate receptors, NMDA receptor, AMPA Receptor, Kinate Receptor, Metabotropic Receptor.

\section{INTRODUCTION}

Schizophrenia is a complex condition which involves dysregulation of various pathways. ${ }^{1}$ The interaction and role of dopaminergic, glutamatergic, GABAergic and cholinergic neurotransmitter systems are very much evident in pathophysiology of this disorder. Key symptoms are divided into two. ${ }^{2}$ Positive symptoms include auditory hallucination delusions, loose associations, disorganized thoughts and behaviors while negative symptoms flat affect, decreased motivation, decreased social interaction. There can be great variation in presentation of these symptoms. ${ }^{3}$ Dopaminergic hyperactivity was mainly emphasized of research regarding neurotransmitter abnormality in schizophrenia and related symptoms. ${ }^{4}$ In normal human being dopamine agonist can produce paranoid delusions but worsens it in this condition. Whereas antipsychotics antagonize dopamine receptors. Oddly enough stimulant treatment can actually mend the negative symptoms of schizophrenia. Dopamine theory is a theory of cortical-subcortical dopamine imbalance with excess sub- cortical dopamine function related with positive symptoms and dopaminergic hypoactivity triggering negative symptoms. Neurotransmitter glutamate combines with Cortical and subcortical structures so its disturbance leads to dissociation of dopaminergic function. There is pharmacological confirmation of glutamatergic hypoactivity in schizophrenia. ${ }^{5}$ Phencyclidine PCP and other dissociative anesthetics cause positive as well as negative psychotic symptoms in normal humans producing a condition which is similar to schizophrenia. ${ }^{6}$ While NMDA receptor dysfunction is proposed in schizophrenia. The primary problem in another receptor subtype that interacts with the NMDA receptor is the reason of apparent NMDA receptor abnormality which causes breakdown of glutamatergic transmission.?

\section{THE GLUTAMATE RECEPTORS -SUBTYPES}

Glutamate receptor consists of four families which includes G-protein coupled metabotropic receptors inotropic receptor families which are 3 in number viz. AMPA kinate and NMDA. Four or five subunits make an inotropic receptor which form ligand gated ion channels. Family of 4 genes make an AMPA subunit receptor which is termed gluR1-gluR4. The mRNA from each gene is expressed in either of the two isoforms i.e. 'flip' and flop', which results from alternative splicing. Also, the final subunit protein has amino acid at specific site in the ion channel which can be modified. Correspondingly, there are chances for heterogeneity in final arranged AMPA receptors which is based on subunit composition. There are various binding sites of assembled AMPA receptors one for glutamate, second for competitive antagonists such as CNQX act and third where desensitization modulators exert their influence. The final receptors have unique pharmacological properties presented by subunit composition. ${ }^{8}$

Kainate receptors are ligand gated ion channels which comprises of subunits derived from genes for low affinity gluR5-gluR7 and high affinity KA1-KA2 subunits. These subunits also go through alternate splicing and editing. The NMDA receptor 
is also a ligand-gated ion channel made of four or five subunits. These subunits are coded by five genes termed NMDAR1 and NMDAR2ANMDAR2D. NMDAR1 is an obligate subunit and is expressed as one of eight isoforms, because of the alternative splicing of exons 5, 21 and 22 13,24 . Transcription of the NMDAR1 subunit then shows a theoretically important level for the regulation of the expression of functional NMDA receptors. ${ }^{9}$ This regulation can stimulate certain properties of final functional NMDA receptors, including the pharmacology of their binding sites. The pharmacological regulation of the NMDA is based on the rare sequence of binding sites on the NMDA receptor 24. Presynaptic glutamate release and post-synaptic depolarization are both required for NMDA receptor firing. Lastly, there is a site within the ion channel related with the binding of non-competitive antagonists of the NMDA receptor, such as PCP, ketamine and MK-801. These antagonists are use-dependent, i.e. the ion channel must be opened, so there must be cooperatively between multiple sites for uncompetitive antagonism to occur. $^{10}$

Binding sites are associated with different subunits and their affinities can vary depending on subunit composition. NMDAR1 homomers forms glycine binding sites, while NMDAR2 subunit apparently needs to form both glutamate and MK-801binding sites. Further, receptors containing NMDAR2A subunits have more affinity for specific glutamate site ligands, while receptors with NMDAR2A or NMDAR2B subunits have greater affinities forMK-801 binding than receptors with NMDAR2C or NMDAR2D subunits. Moreover, NMDA receptors with particular NMDAR1 splice variants have greater affinity for MK-801 than receptors with others, irrespective of NMDAR2 coassembly. Receptors with NMDAR2B subunits are actually linked with higher affinity for polyamine modulators. Thus, differential subunit combinations presents exceptional binding properties to the NMDA receptors. ${ }^{11}$

Metabotropic glutamate receptors are basically seven trans membrane domain, G-protein coupled receptors having similarities with most dopamine, serotonin and norepinephrine receptors. They are coded by eight genes named mGluR1-mGluR8, few of them go through alternative splicing. They are categorized into three, type $1 \mathrm{mGluR} 1$ and 5, type II. mGluR2 and 3 and type III mGluR4, 6, 7 and 8, each one seems to have precise functions. The four glutamate receptor subtypes have unique regional and synaptic distributions. AMPA receptors are chiefly postsynaptic. They are extensively distributed in cortex, ventral striatum, temporal lobe structures like hippocampus and amygdala, with lower levels in the thalamus. Kainate receptors are predominantly presynaptic and possibly control glutamate release. The distribution varies a bit from that of AMPA receptors. ${ }^{12}$ The hippocampal CA3 subfield and infragranular layers of cortex has augmented binding, but comparatively less binding than AMPA in other parts. NMDA receptors are chiefly postsynaptic and they are colocalized with AMPA receptors. There is an overlapping in distribution of these two receptor subtypes. Distribution and function is the main difference in Metabotropic receptor families Group I receptors are apparently postsynaptic receptors: mGluR1 receptors are maximum in hippocampus and thalamus, fewer in cortex and ventral striatum; mGluR5 receptors are rich in cortex, ventral striatum, temporal lobe structures like hippocampus and amygdala and thalamus. Group II and III receptors are presynaptic modulators which release glutamate. mGluR3 is single metabotropic subtype expressed on glia and mGluR2 is restricted to cortex and dentate gyrus. ${ }^{13}$

\section{GLUTAMATE RECEPTOR EXPRESSION IN SCHIZOPHRENIC BRAIN}

After knowing the chance of glutamate receptor dysfunction in schizophrenia, the expression of all four families of the glutamate receptors has been thoroughly studied in schizophrenic brain. The main aim of these examinations are limbic regions associated with schizophrenia, chiefly limbic cortex, striatal areas and medial temporal lobe structures ${ }^{14}$ Various levels of gene expression were targeted, like subunit mRNA and sprotein levels and also final binding sites. Following are the studies that have been published for each receptor subtype in postmortem schizophrenic. ${ }^{15}$

\section{AMPA receptors}

This particular receptor has that been studied the most is glutamate receptors. It is the spot of one of the most reliable findings in the schizophrenic brain. When AMPA-linked subunits were cloned first, the illustration of the mRNA encoding the gluR1 subunit in the schizophrenic medial temporal lobe was studied by Harrison. Constant decrease in the expression of this subunit transcript in hippocampal regions, which is an anomaly that was statistically important in CA3. ${ }^{16}$ They also established that gluR1 subunit mRNA is reduced in multiple hippocampal subfields dentate gyrus, CA3, CA4 and in the subiculum. It was also stated that gluR2 subunit mRNA is reduced in the medial temporal lobe in schizophrenia, mainly in the para hippocampal gyros. In gluR1 and gluR2, the splice variants are named as flip and flop. By defining the patterns of expression of these isoforms the study of AMPA receptor expression in the medial temporal lobe was further continued by Harrison.

Reduction in expression of gluR2 subunit mRNA in hippocampal structures was mentioned in recent reports and established that both the flip and flop variants were decreased, the flop to a great outspread. Numerous latest findings studied the expression of the AMPA subunit proteins in the medial temporal lobe in schizophrenia. With the help of quantitative immunocytochemical analyses, Eastwood and colleagues repeated their earlier conclusions of reduced expression of the AMPA subunits in medial temporal lobe structures. ${ }^{17}$ Specifically, gluR1 immunoreactivity was considerably decreased in the para hippocampal gyros and all together gluR2r3 immunoreactivity reduced in the CA4 subfield of the hippocampus. Conversely Breese et al. stated no change in gluR1, gluR2, or gluR3 immunoreactivity characteristic to schizophrenia using Western analysis in hippocampal samples. With the help of $\mathrm{H}$ CNQX to label the AMPA receptor, Kerwin and company stated reduced binding to the AMPA receptor in the schizophrenic hippocampus, mostly in the CA3 and CA4. Taking all of the studies in consideration it implies that there is reduced AMPA receptor expression in the medial temporal lobe in schizophrenia, a reduction relating change of subunit gene expression and also the final binding site. It is known recently that none of the AMPA-linking subunit transcripts are altered in striatal sub regions caudate, putamen and nucleus accumbens in schizophrenia. Subunit protein levels have not been testified in striatal regions till now. In striatal regions binding to the AMPA receptor has been regulated, but the outcome varies. Noga and company stated enhanced AMPA binding, using H CNQX, in caudate, putamen and accumbens in schizophrenia. The cortex was also examined for changes of AMPA receptor expression in schizophrenia. Absolutely no difference in the expression of the AMPA-linked subunit mRNAs in prefrontal or occipital cortex in schizophrenia, even though Sokolov stated reduced gluR1 mRNA in superior frontal gyrus using RT-PCR. Concluding all the studies and researches AMPA receptor expression in schizophrenic brain states reduced AMPA receptor expression in the medial temporal lobe, slight or negligible if present any, differences in cortex and striatum. ${ }^{18}$

\section{Kainate receptors}

The kainate receptor is a ligand-gated ion channel like the AMPA receptor, made of association's of the gluR5-gluR7, KA1 and KA2 subunits. Reduced expression of gluR6 and KA2 mRNA in some hippocampal regions was uncovered by Porter et al. with matching data for the AMPA subunits in the medial temporal lobe and gluR6 mRNA 
was not altered in the schizophrenic cerebellum. ${ }^{19}$ According to a study gluR7 and KA1 subunit transcripts are reduced in the superior frontal gyros in schizophrenics, just like the subunits of the AMPA and NMDA receptors. GluR5 was studied by Western analysis and was not changed in schizophrenic hippocampus. Over all, kainate receptor binding has been seen to be increased in various cortical areas in schizophrenia $12,41,52$, reduced in the hippocampus and para hippocampal gyros 31 and unaltered in striatal sub regions 41,42 . With very less information we conclude, this receptor has shows anomaly in expression like AMPA receptor. $^{20}$

\section{NMDA receptors}

The NMDA receptor is a ligand-gated ion channel just like AMPA and kainate receptors formed by association of subunits named NMDAR1, $2 \mathrm{~A}, 2 \mathrm{~B}, 2 \mathrm{C}$, and $2 \mathrm{D}$. The study of the NMDA binding sites is extensively more complicated than AMPA and kainite receptors. Using H MK-801, very few changes were found. Enhanced $\mathrm{H}$ MK-801 binding was reported in the schizophrenic putamen, noted in frontal cortex or in multiple medial temporal lobe regions, including the hippocampus, amygdala and entorhinal cortex no changes were found. ${ }^{21}$ In multiple cortical areas, putamen or cerebellum there were no alterations present according to another recent study. The primary agonist site for glutamate 3 has been observed with $\mathrm{H}$ glutamate in the hippocampus and no alterations were seen in schizophrenia. The glycine co-agonist site has also been studied. By using $3 \mathrm{H}$ glycine, Ishimaru and colleagues stated more binding in multiple cortical areas in schizophrenia. In recent times, in striatum

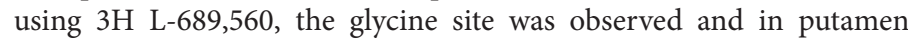
enhanced binding was seen. ${ }^{22}$

\section{Metabotropic receptors}

They are coded as a single protein molecule and are all members of the seven trans membrane domain, G-protein coupled receptor family. In prefrontal cortex the mRNAs coding the metabotropic receptors mGluR3 and mGluR5 were quantified. ${ }^{23}$ Although mGluR3 mRNA was not altered in schizophrenia in multiple areas of the prefrontal cortex, mGluR5 was enhanced in the orbitofrontal cortex Brodmann area 11, but not in areas 9 or 10. After Cellular analysis it was revealed that this increase was due to enhanced expression of mGluR5 mRNA in pyramidal cells in lamina III of this area of prefrontal cortex. ${ }^{24}$

\section{CONCLUSION}

Regardless of various unpredictable reports, there are numerous findings which seem to be quite reliable. Firstly AMPA receptor is abnormally expressed in schizophrenic brain appears specifically to hippocampus and is generally absent in cortex and striatum. Due to reduction of medial temporal lobe AMPA receptor expression there is deficiency which also includes subunit mRNA and protein levels, also the final binding sites. Secondly in hippocampus kinate receptor is decreased while may be increased in cortical region. Thirdly there is an abnormal expression of the obligate NMDAR1 subunit in schizophrenic cortex. Concluding these reports validates the hypothesis of abnormal glutamatergic neurotransmission in schizophrenia with major contribution of ionotropic receptors. These studies give indication that alteration of receptors may establish therapeutic utility and treatment of disorder.

\section{CONFLICT OF INTEREST}

We wish to confirm that there are no known conflicts of interest associated with this publication and there has been no significant financial support for this work that could have influenced its outcome

\section{ABBREVIATIONS}

gluR5: Glutamate Receptor 5; gluR7: Glutamate Receptor 7; KA1: Kinate Receptor 1; NMDAR1: N-methyl-D-aspartate Receptor 1, N-methyl-Daspartate Receptor 2A, N-methyl-D-aspartate Receptor 2D.

\section{REFERENCES}

1. Lunn B. Schizophrenia. In: Psychiatry by Ten Teachers, Second Edition. 2017.

2. Castañé ,Adell A. Schizophrenia. in Receptors. 2018.

3. Grace AA. Dysregulation of the dopamine system in the pathophysiology of schizophrenia and depression. Nat Rev Neurosci. 2016;17(8):524.

4. Lodge DJ, Grace AA. Hippocampal dysregulation of dopamine system function and the pathophysiology of schizophrenia. Trends in Pharmacological Sciences. 2011;32(9):507-13

5. Tost H, Alam T, Meyer-Lindenberg A. Dopamine and psychosis: Theory, pathomechanisms and intermediate phenotypes. Neurosci Biobehav Rev. 2010;34(5):689-700.

6. Lakhan SE, Caro M, Hadzimichalis N. activity NMDA receptor in neuropsychiatric disorders. Front Psychiatry. 2013;4:52.

7. Coyle JT. NMDA receptor and schizophrenia: A brief history. Schizophr Bull. 2012;38(5):920-6

8. Abuin L, Bargeton B, Ulbrich $\mathrm{MH}$, Isacoff EY, Kellenberger S, Benton R. Functional architecture of olfactory ionotropic glutamate receptors. Neuron. 2011,13;69(1):44-60.

9. Falcón-Moya R, Sihra TS, Rodríguez-Moreno A. Kainate receptors: Role in epilepsy. Front Mol Neurosci. 2018;11:217.

10. Jaremko W, Huang Z, Karl N, Pierce VD, Lynch J, Niu L. A kainate receptor-selective RNA aptamer. J Biol Chem. 2020;295(19):6280-8.

11. Wu H, Gao S, Terakawa S. Inhibitory effects of fucoidan on NMDA receptors and l-type $\mathrm{Ca}^{2+}$ channels regulating the $\mathrm{Ca}^{2+}$ responses in rat neurons. Pharm Biol. 2019;57(1):1-7.

12. Akkus F, Treyer V, Ametamey SM, Johayem A, Buck A, Hasler G. Metabotropic glutamate receptor 5 neuroimaging in schizophrenia. Schizophr Res. 2017;183:95-101.

13. Caraci F, Nicoletti F, Copani A. Metabotropic glutamate receptors: the potential for therapeutic applications in Alzheimer's disease. Curr Opin Pharmacol. 2018;38:1-7.

14. Lum JS, Millard SJ, Huang XF, Ooi L, Newell KA. A postmortem analysis of NMDA ionotropic and group 1 metabotropic glutamate receptors in the nucleus accumbens in schizophrenia. J Psychiatry Neurosci. 2018;43(2):102.

15. Stansley BJ, Conn PJ. The therapeutic potential of metabotropic glutamate receptor modulation for schizophrenia. Curr Opin Pharmacol. 2018;38:31-6

16. Bettler B, Collingridge GL, Dingledine R, Heinemann SF, Hollmann M, Lerma $\mathrm{J}$, et al. Ionotropic glutamate receptors (version 2019.4) in the IUPHAR/BPS Guide to Pharmacology Database. IUPHAR/BPS Guide to Pharmacology CITE. 2019;2019(4).

17. Pacheco A, Aguayo FI, Aliaga E, Muñoz M, García-Rojo G, Olave FA, et al. Chronic stress triggers expression of immediate early genes and differentially affects the expression of AMPA and NMDA subunits in dorsal and ventral hippocampus of rats. Front Mol Neurosci. 2017;10:244.

18. Bhattacharya S, Kimble W, Buabeid M, Bhattacharya D, Bloemer J, Alhowail $A$, et al. Altered AMPA receptor expression plays an important role in inducing bidirectional synaptic plasticity during contextual fear memory reconsolidation. Neurobiol Learning Memory. 2017;139:98-108.

19. Litwin DB, Carrillo E, Shaikh S, Berka V, Jayaraman V. The Structural Arrange ment and Dynamics of Homomeric Kainate Receptors Determined by smFRET. Biophysical J. 2019;116(3):105a.

20. Catts VS, Lai YL, Weickert CS, Weickert TW, Catts SV. A quantitative review of the postmortem evidence for decreased cortical N-methyl-d-aspartate receptor expression levels in schizophrenia: How can we link molecular abnormalities to mismatch negativity deficits?. Biol Psychology. 2016;116:57-67.

21. Song $X$, Jensen $M \varnothing$, Jogini $V$, Stein RA, Lee $C H$, Mchaourab HS, et al. Mechanism of NMDA receptor channel block by MK-801 and memantine. Nature. 2018;556(7702):515-9

22. Zhu S, Stein RA, Yoshioka C, Lee CH, Goehring A, Mchaourab HS, et al. Mechanism of NMDA receptor inhibition and activation. Cell. 2016;165(3):704-14.

23. Reiner A, Levitz J. Glutamatergic signaling in the central nervous system: Ionotropic and metabotropic receptors in concert. Neuron. 2018;98(6):1080-98.

24. Roth BL. Molecular pharmacology of metabotropic receptors targeted by neuropsychiatric drugs. Nat Struct Mol Biol. 2019;26(7):535-44.

Cite this article: Lodha S, Upadhyay S, Baghel KS, Ahmad Y. Role of Glutamate Receptor in Schizophrenia. Free Radicals and Antioxidants. 2020;10(1):1-3. 